Georgia State University

ScholarWorks @ Georgia State University

\title{
To Control or Be Controlled: Predicting Types of Offending in a Corporate Environment Using Control-Balance Theory
}

Donald E. Hunt

Georgia State University

Volkan Topalli

Georgia State University

Follow this and additional works at: https://scholarworks.gsu.edu/cj_facpub

Part of the Criminology and Criminal Justice Commons

\section{Recommended Citation}

Hunt, Donald E., and Volkan Topalli. 2019. To Control or Be Controlled: Predicting Types of Offending in a Corporate Environment Using Control-Balance Theory. Journal of Quantitative Criminology, 35:435-464.

This Article is brought to you for free and open access by the Department of Criminal Justice and Criminology at ScholarWorks @ Georgia State University. It has been accepted for inclusion in CJC Publications by an authorized administrator of ScholarWorks @ Georgia State University. For more information, please contact scholarworks@gsu.edu. 


\section{To Control or Be Controlled: Predicting Types of Offending in a Corporate Environment Using Control-Balance Theory. \\ INTRODUCTION}

Sutherland $(1947,1949)$ distinguished white collar criminality from traditional crime by focusing on how and why professional settings and occupations provided unique opportunities for white collar crime (WCC) in the same way that impoverished settings and pursuits did for traditional crime. In the white collar world, crime occurred when a business professional acted against client or company interests, and in a manner that capitalized on the individual's position within the organization. But for the opportunities afforded by that position, the perpetrator could not commit such offenses (Sutherland, 1947). Braithwaite (1985) expanded upon this notion by defining corporate crime (not simply white collar crime) as involving a corporate employee, working under the umbrella of a legitimate function of the corporation, but acting in a manner that would otherwise be considered criminal by applicable law. Theories that describe this type of deviance as distinct from other types of crime are rare. Rarer still are those that systematically distinguish between WCC and more traditional forms of crime. One exception is Tittle's $(1995,2004)$ control balance (CB) theory, which proposes WCC and traditional crime can be explained through a consideration of ratios of control surpluses and control deficits that would-be offenders experience in their day-to-day operational environments.

\section{Control Balance Theory and White collar Crime}

Since Sutherland delivered his American Sociological Association presidential keynote address in 1939, criminological thinking has focused generally on two types of deviance; traditional street crime and white collar crime (Benson, Madenson, \& Eck, 2009; Geis, 1991; Shichor, Gaines, \& Schoepfer, 2012; Simon \& Eitzen, 2002). Sutherland considered white collar crime to include such behaviors as fraud, insider trading, stealing corporate secrets, investment schemes, and labor law violations (Sutherland, 1949). Later 
research expanded this definition to encompass more modern offenses such as cybercrime, corporate money laundering, and insider trading with the idea that these crimes could not occur outside a corporate setting (Benson, 1985; Benson \& Moore, 1992; Geis, 1993; Graber, 1980; Rosoff, Pontell, \& Tillman, 2002), giving rise to the field of occupational crime research (Friedrichs, 2002, 2009; Green, 1997, O’Grady, 2011). Conversely, what we refer to as traditional street crimes (Southerland's blue-collar crimes) include offenses captured in the Uniform Crime Report such as homicide, sexual assault, robbery, embezzlement, forgery, and theft. These offenses do not require a corporate or occupational setting to take place (Clarke, 1997; Sutherland, 1949). Whereas, the traditional crimes such as theft and forgery are not dependent on a pre-existing corporate or occupational condition, fraud and insider trading typically are.

The distinction between these deviance categories is further manifested in their disparate prosecution and sentencing characteristics (Coleman, 2005; Reiman \& Leighton, 2002; Richman, 2012; Simpson, 2013). For this and other reasons, few crime theories are formulated to explain or predict both street and white collar crime, with street crime accorded the bulk of theory development. Most often, scholars call upon a theory originally meant to explain traditional street offending and extend it to apply to white collar criminality (Shichor, Gaines, \& Schoepfer, 2012).

Sutherland $(1941,1947)$ was himself prone to this approach. While he designed differential association theory to address traditional crime,${ }^{1}$ stating that all crime is a learned behavior, he later went on to apply the basic tenets of the theory to both traditional and white collar offending, and subsequent research has followed his lead (Coleman, 1987, Cressey, 2012; Klenowski, Copes, \& Mullins, 2011; Piquero, Tibbetts, \& Blankenship, 2005). Gottfredson and Hirschi $(1987,1990)$ made a similar argument three decades later with their

\footnotetext{
${ }^{1}$ Sutherland, by his own admission, stated he never meant to spark the divide between traditional and white collar crime (Shichor, Gaines, \& Schoepfer, 2012).
} 
general theory of crime (GTC). Though its original formulation focused on the explanation of traditional crime, they later asserted that the theory's concepts should extend also into WCC because low self-control applies to all behavior and in every environment. Empirical tests of this expanded focus of GTC, though, show mixed results (Benson \& Moore, 1992; Geis, 2000; Pratt \& Cullen, 2000).

Tittle's CB theory $(1995,2004)$ is somewhat unique in that it was originally formulated to account for the etiology of both traditional and WCC within a single framework. Ironically, most subsequent research applied the theory to explain traditional deviance (see e.g., Piquero \& Hickman, 1999, 2003; Hickman \& Piquero, 2001; Hickman, Piquero, Lawton, \& Greene, 2001; Higgins \& Lauterbach, 2004; Higgins, Lauterbach, \& Tewksbury, 2005). ${ }^{2}$ This, despite Tittle's contention that much deviance occurs within commercial settings, where opportunities for both traditional and white collar deviance are present.

Introduced in $1995, \mathrm{CB}$ theory has garnered measurable attention ${ }^{3}$. It is centrally focused on how control dictates behavioral responses to criminal opportunities in an individual's environment. In Tittle's formulation, control is a ratio of two factors; the degree to which other people and one's environment control a person's behavioral options, and the extent to which one can exercise the same over others. Importantly, the ratio of these two forms of control determines both whether deviance occurs and the nature of that deviance.

Control deficits occur when the amount of control over a person exceeds the amount of control they can exercise. Control surpluses occur when the amount of control a person can exert surpasses the control to which they are subject. According to Tittle (1995), when these controls are equally balanced, deviance is unlikely because the amount of control a person has

\footnotetext{
${ }^{2}$ Possibly the result of there being far more data available on traditional crime versus corporate crime.

${ }^{3}$ Cited nearly 500 times since its original publication.
} 
over others and their environment offsets the amount of control others and the environment have over them.

Control deficits lead to defiance (e.g., “...illustrative acts such as youthful violation of curfews, vandalism, and status restriction, mocking denigrations of company officials by striking workers...”), predation (e.g., “...theft, rape, homicide,... and fraud...”), and submission (e.g., “...helping repress others to please power holders...”) (Tittle, 1995; pgs. 138,137 , and 140 respectively). These types of deviance have in common the motivation to restore or establish a kind of balance and can be thought of as "oppositional" or "restorative" in nature. This is because the individuals in this condition have little or no access to more sophisticated forms of redress that can be attained through the exploitation of privilege, experience, or access and therefore deviate within the confines of those limited opportunities available to them and most others at the organizational "bottom of the ladder".

Control surpluses are associated with "autonomous" deviance (Tittle, 1995) such as those found more commonly in the white collar world because these individuals possess the tools, access, and information necessary to conduct this type of activity (Tittle, 2004). Here the motivation to engage in deviance is a product of one's status and access to offending opportunities. The greater the imbalance in this direction, the greater the motivation to exploit these more sophisticated types of opportunities. Tittle posited that corporate environments are one of the more likely settings where these types of deviances - exploitative (e.g., "...acts of corporate price fixing, profiteering from manufacturing processes that endanger workers, influence peddling... when those acts involve coercion, manipulation... without regard for the

\footnotetext{
${ }^{4}$ Note that in his critique of Tittle's work, Braithwaite has argued that Tittle's use of these three outcomes defiance, predation, and submission - were defined in a way that was cohesive or testable. Our stance is that the three concepts have in common a desire on the part of the individual experiencing control deficit to restore or achieve balance. Thus, we refer to control deficits as producing "restorative" motivations on the part of the individual, subsequently brought about by engaging in acts that harm or take advantage of the organization in a manner that is both emotionally satisfying and instrumentally valuable to the offender. This motivation to restore balance is also of course at the core of Braithwaite's own theories, but in those cases, restoration is produced through formal means with the goal of producing a different kind of balance.
} 
desires or the welfare of the exploited.”), decadence (e.g., “...humiliating people for entertainment...), and plunder (e.g., “...massive pollution by giant oil companies with accompanying price increases to recover costs of cleanup...) - should occur (Tittle, 1995, pgs. 138,139 respectively; 2004) because these actors have intimate knowledge and access to company systems that outsiders would not have.

Stated earlier, despite Tittle's contention that CB theory should be applied to both white collar and traditional crime, it has been more common for it to be applied to traditional forms of crime and victimization, (Baron \& Forde, 2007; DeLisi \& Hochstetler, 2002; Piquero \& Hickman, 1999, 2003; Hickman \& Piquero, 2001; Hickman, Piquero, Lawton, \& Greene, 2001; Higgins \& Lauterbach, 2004; Higgins, Lauterbach, \& Tewksbury, 2005; Nobles \& Fox, 2013; Piquero, 2001; Savelsberg, 1999; Wood \& Dunaway, 1997). To date, only one study has explored CB theory as an explanation for deviance in the corporate environment. Piquero and Piquero (2006) examined deviance among hypothetical sales force managers by asking eighty-seven graduate-level business students to consider a variety of scenarios created to test corporate deviance from either a control surplus or deficit. The vignettes presented participants situations and asked them to decide whether or not to exploit an entry-level ${ }^{5}$ subordinate by encouraging the employee to inflate sales statistics. The results indicated that those with a control surplus, as compared to those with a control deficit, were more likely to have the intention to exploit the novice worker confirming part of CB theory (Piquero \& Piquero, 2006).

Importantly, Piquero and Piquero (2006) recommended that actual corporate sales representatives (SR) data would be preferable to their student-based sample, as the former would provide improved external validity and comprehensiveness. Tittle (2004) also noted that one of the reasons so few analyses of CB theory exist is that typical datasets did not

\footnotetext{
${ }^{5}$ Less tenured.
} 
comprehensively account for all the kinds of information necessary to construct adequate measures or operationalize the concepts to test the theory in toto. These points reveal fundamental complications scholars have yet to overcome with regard to testing CB theory. First, corporate data are difficult to obtain. Companies are protective of their private information. Material of this nature, should it become public, might pose a host of risks. Second, when data are available they rarely contain the information necessary to operationalize a control surplus and a control deficit simultaneously, especially in the same setting.

There is a third issue to which we alluded earlier. CB theory not only predicts when offending will occur but, as well, the nature of the offending that will occur (i.e., autonomous or oppositional deviance). This more innovative aspect of theory is often acknowledged by researchers but not tested, again because of limitations in data, though also due to commonly accepted paradigms associated with theory testing in general. Traditional theory testing is primarily a deductive exercise where researchers commonly operationalize variables in collected data and judge a theory's worthiness based on the statistical strength of the relationship between independent and dependent variables. The majority of criminological theories are concerned with when or how much offending will occur under manipulated or observed circumstances, and such tests often allow for the comparison of offending and nonoffending groups. CB theory is formulated differently. It predicts differential levels offending as well as differential types of offending based on variability in control exerted by and applied to the potential offender. As such, comprehensive "testing" of CB theory should involve more than simply identifying statistical significance between the independent and dependent variables. It should also test whether different levels of control surpluses or deficits result in different kinds of offending. It is this challenge that we take up in the current paper. 
One strategy would be to focus on offenders. This is a common practice in qualitative research involving traditional crime (such as street offending), where inductive processes are employed to explore not only the decision to offend but also the manner in which that offending takes place. Qualitative researchers are sometimes accused of "sampling on the dependent variable" by focusing their data collection only on those who offend, but this approach makes sense if one is trying to understand the nature of offending itself (see e.g., Wright \& Decker, 1994; Jacques, 2014). Given the unconventional structure of CB theory, with its emphasis not only on offending propensity but also on offending specificity, a similar approach would seem a warranted and potentially fruitful endeavor. Our goal in the current paper was to apply CB theory to a real-world set of data based in the corporate world, allowing us to better understand the etiology of offending in a WCC setting, (i.e., not whether offending will occur but how it will occur). This approach also allowed us to examine whether CB theory had specific descriptive validity with relation to WCC rather than simply as a general theory of offending. To address these goals, we attained access to data comprised entirely of offenders in a corporate setting who vary along the parameters set forth in $\mathrm{CB}$ theory (i.e., a sample that includes offenders with control deficits and those with control surpluses).

\section{Current Study}

In keeping with notion of applying $\mathrm{CB}$ theory to settings that maximize external validity and comprehensively provide for control surpluses and deficits (Piquero \& Piquero, 2006; Tittle 2004), we rely on case files from a United States financial institution containing the actual investigations of SR deviance by the company's corporate security department. These data span eight years and consist of 445 "founded investigations" (equivalent to police clearance). 
The corporation in question is best described as a customer-facing financial services provider. It offers products primarily in the electronic transactions industry and solicits its services to customers via commission-based SRs coast-to-coast. The organization divides its sales organization into an inside sales force located within corporate headquarters and an outside sales force ${ }^{6}$ positioned in all 48 contiguous states. Also, as one would expect, the entire sales force consists of SRs with varying levels of company tenure. We employed Tittle's (1995; pg. $188 \&$ 190) conceptualizations of deviance to identify how the offenses committed by each of these SRs in our data could be assigned to either an autonomous or repressive category.

Autonomous deviance occurs when individuals have a control surplus. Such offending is more strongly associated with white collar and corporate settings where individuals are often able to exploit advantages afforded them by their position within the institution. Repressive deviance is more likely to occur among those denied such levels of control, often associated with "traditional" or "street settings" where individuals engage in deviance in response to excessive or "unfair" levels of control (Tittle, 1995, 2004). But, a careful reading of Tittle's theory clearly intimates that both forms of deviance can take place within corporate and white collar settings, with repressive deviance occurring when individuals within the organization are heavily controlled and lack access to the kinds of opportunities available to those higher up in the organization. In fact, this was borne out in the data that we employed in the current study.

\footnotetext{
${ }^{6}$ Made up of SRs working from their homes. It is important to note that there were no systematic differences between inside and outside SRs in terms of tenure. Nor were there differences in how someone was assigned to inside or outside status (i.e., based on qualifications or tenure). SR assignment is based purely by the needs of the company and the geographical location of the sales rep. The company only hires inside sales reps in its home base city because they are local and the sales department is housed at company HQ. The outside sales force spans the entire country, including the home base city but they are assigned using the same standards used nationally, limited by geographical location.
} 
With the sales position and tenure metrics set, we were able to test $\mathrm{CB}$ theory by means of four hypotheses for the type of SR control imbalance relative to the type of deviance observed (see Figure 1). The company structure is such that SRs with higher tenure have higher levels of experience with the corporation's inner workings; its policies, regulations, processes, network of employees and the company's organizational structure. Their ability to understand the functions and players within the corporate system afford them greater latitude to take advantage of the corporate system. Experienced SRs are better able to avoid detection and sanctions, and able to engage in more complex forms of deviance. As such, they clearly possess a surplus of control. In contrast, lower tenured SRs lack this experience and access. They have permission only to lower level processes and systems that allow for a different kind of deviance, and they lack the deeper and more extensive experience required to exploit such systems in more complex ways. As well, their lack of experience makes it more likely they would be detected and sanctioned for attempting the kinds of deviance perpetrated by more sophisticated colleagues. Finally, lower experience employees have less employment security, as they are more easily let go than experienced employees if adjustments to the company workforce are required. The corporation clearly has the upper hand over such employees, preventing them from exerting the same amount of control over their circumstances in opposition to the corporation's control; a deficit. Thus, we present the first hypothesis in the following, two-tiered form.

$\mathrm{H}_{1 \mathrm{a}}$ : SRs with higher levels of company tenure have a control surplus that leads to higher odd of autonomous deviance.

$\mathrm{H}_{1 \mathrm{~b}}$ : SRs with lower levels of company tenure have a control deficit that leads to higher odds of repressive deviance.

Further, the level of control an SR has over their day-to-day occupational circumstances is also a direct reflection of whether they are assigned to the inside sales force 
or the outside sales force. Inside SRs are under the direct observation and scrutiny of their peers and supervisors. They have far less latitude in when and where they are able to access systems, and they are more likely to be questioned about day-to-day activities as a result of their frequent "face-time" at the company headquarters. Senior sales management within the company confirmed that the corporation has much less control over the behavior and circumstances of the SRs assigned to its outside sales force as opposed to those assigned to the inside sales force. ${ }^{7}$ Based on this information, the second hypothesis followed.

$\mathrm{H}_{2 \mathrm{a}}$ : SRs with an outside sales position experience a control surplus that leads to higher odds of autonomous deviance

$\mathrm{H}_{2 b}$ : SRs with an inside sales position experience a control deficit that leads to higher odds of repressive deviance.

Figure 1. Hypotheses flowchart

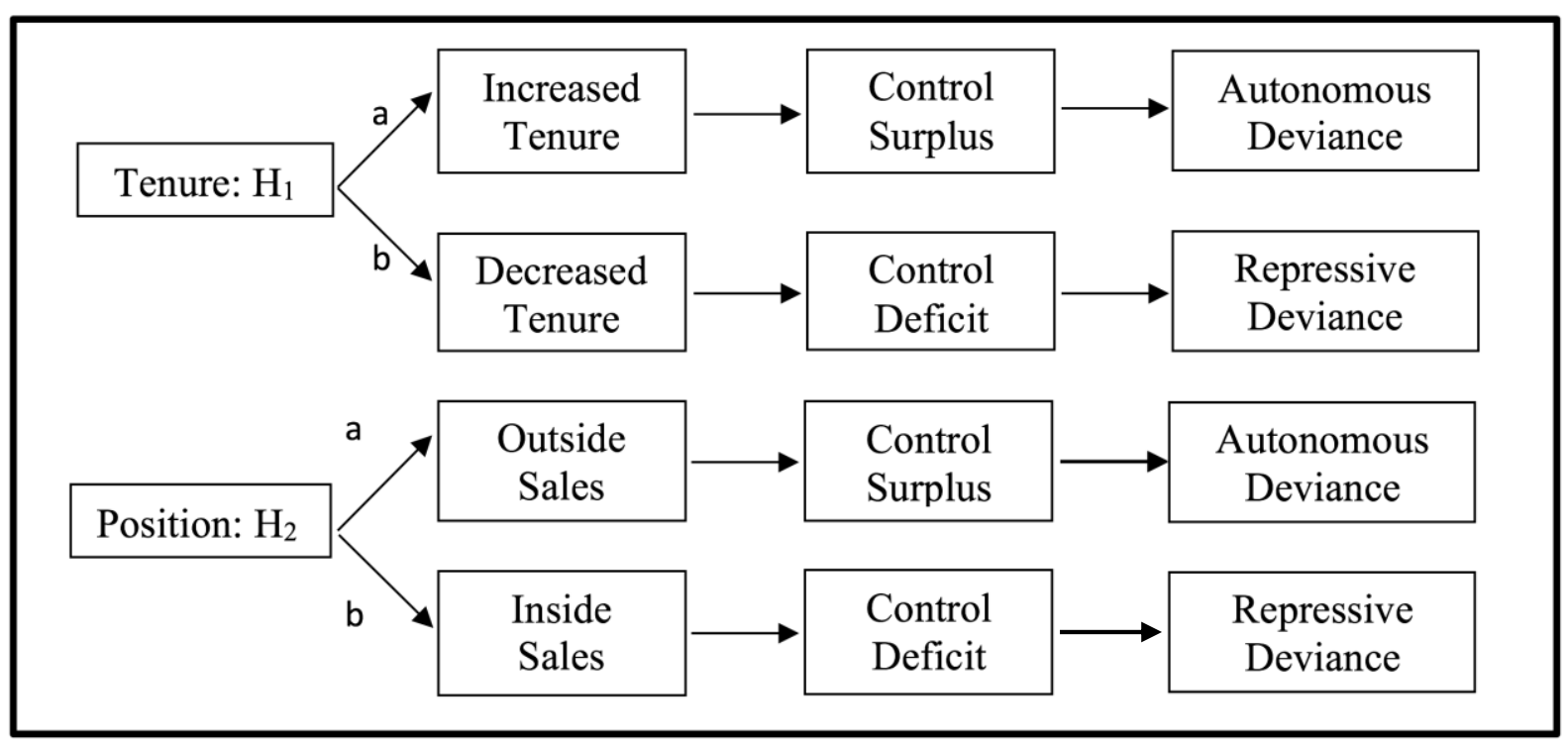

CB theory predicts the least amount of deviance will occur when the amount of control exercised on an individual is equal to the amount they can impose; in a theoretically perfectly balanced system, deviance would be zero. As the tension between these two forces becomes skewed (i.e., falls out of balance), the amount of offending will deviate from zero with the

\footnotetext{
${ }^{7}$ Confirmed to the authors from senior level management via personal correspondence.
} 
type of offending expressed - autonomous vs. repressive - based on the type of control imbalance experienced. Thus, as potential offenders are exposed to control surpluses, their propensity to offend autonomously will increase. Alternatively, as potential offenders are exposed to control deficits, their propensity to offend repressively increases apace. As we are employing data comprised entirely of reports of verified deviance, the level of offending would be lowest (but not zero) at the balance point and highest where imbalance was the greatest, i.e., the same "U-shaped" pattern is predicted but shifted upwards from what we might obtain from data including offenders and non-offenders ${ }^{8}$. It is possible to visualize the combined outcomes of deviance level and deviance type in the following manner (Figure 2).

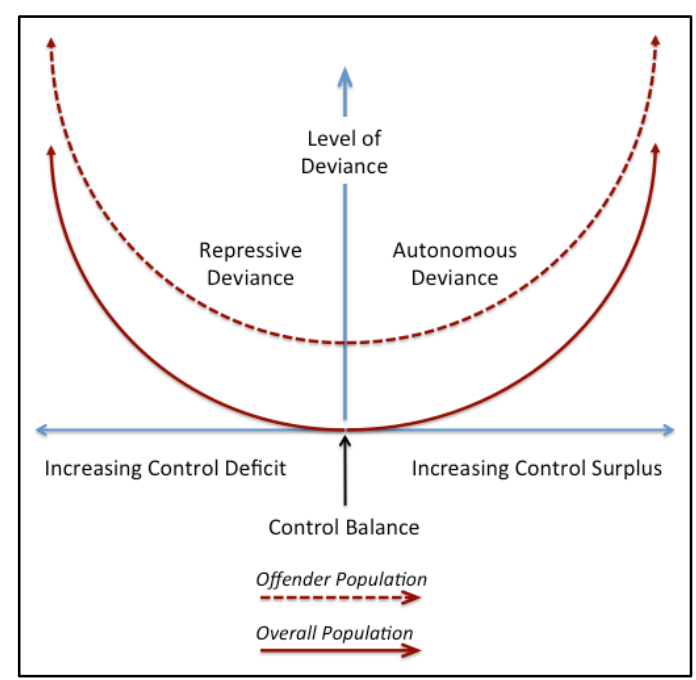

Figure 2.

\section{METHOD}

\section{Setting}

Through its sales force, the corporation adds upwards of 30,000 new customers to its portfolio annually. The company implements and facilitates consumer and business-tobusiness transactional commercial systems for corporate consumers through e-verification and software- and hardware-based processes. Because the company operates nationwide, it relies

\footnotetext{
${ }^{8}$ Tittle acknowledged that there were baseline differences between offenders and non-offenders (i.e. dispositional tendencies to offend) by pointing out the combined effects of predisposition toward offending and situational provocations for offending (see Tittle, 1995, pg. 172).
} 
on the sales force to verify that customers are conducting a legitimate business. SRs carry the necessary paperwork with them to begin the onboarding process which includes requisite signatures, items related to the type of business the customer conducts, inventory, sales volume, demographics, and information pertaining to business ownership, collateral, and creditworthiness. The SR then transmits this information electronically to the corporation's automated risk management system where the process of vetting and boarding the customer begins. This process is both rapid and efficient, lessening the time it takes to implement a transactional system, begin realizing a profit, and for the SR to receive a commission. Yet, with this efficiency comes an inherent weakness. While a rapid and automated system is necessary for success in the current technology-driven market, it carries with it certain vulnerabilities to deviance by its sales force (Kownatzki, Walter, Floyd, \& Lechner, 2013).

\section{Population}

The corporation assigns each of its SRs to either the inside or outside sales force. The sole criteria behind this decision is the company's needs at the time, exclusively based upon the location of the applicant. Only those who live in the immediate vicinity of the official company headquarters would be considered for an inside position as this department is housed specifically in that structure and requires a physical presence during working hours. All other applicants would be considered only for an outside sales position.

Beyond location, the only differences between the inside and outside sales forces come in the form of office environment, lead generation, and quotas. These SRs offer the same services with the same commission structure. Each of them has equal access to the corporation's customer database. Moreover, although SRs may reside in different parts of the country, there are no geographic boundaries in terms of potential customers. Regional borders exist solely to define an SR's management chain.

\section{Positional status and control}


The outside sales force consists of SRs spread across the US and operate remotely from corporate headquarters. Working from home offices, they are essentially free to set their own hours. Communication with their managers is seldom in person, customarily taking place by phone, text, or email. In fact, these SR's managers often do not even reside in the same city. Outside SRs work "in the field" and must cultivate relationships, generate their own leads, and make sales without the day-to-day assistance or oversight of close management. Consequently, their monthly sales quotas are lower than those of the inside sales force. Because of each of these factors, outside SRs are able to exert more control over their occupational environment and circumstances than can the corporation. Thus, a control surplus state exists for these SRs. Under these conditions, CB theory dictates their deviance should occur in autonomous form (Tittle, 1995).

In contrast to the control surplus outside SRs possess, inside SRs typically operate under control deficit conditions. They have desks located inside the operations center of company headquarters where their direct, upper, and even executive managers are all in close proximity and ever-present, corresponding to a high level of supervision. These SRs have set working hours and, unlike their outside sales force counterparts, the management monitors, records, and reviews their telephone conversations with potential customers regularly. Moreover, because company generated sales leads are funneled to the inside sales force, these SRs have higher monthly quotas. Consequently, the corporation clearly exerts more control over inside SRs as compared to the control they can employ and inside SRs can be said to experience an occupational control deficit. According to Tittle (1995), the deviance displayed by inside SRs should therefore be characteristically repressive.

\section{Tenure and control}

Position within the sales force is not the only factor that determines whether SRs experience a control surplus or deficit. Company tenure also affects the control balance ratio. 
An SR experiences a fixed, dichotomous control surplus or deficit regarding their inside or outside sales position. Tenure with the company however, represents a continuum where newer employees are hypothesized to experience control deficits due to enhanced oversight and limited access to corporation systems. Meanwhile, more tenured employees experience greater autonomy by virtue of lesser levels of management resulting in a control surplus. This sliding scale has the added advantage of passing through the area Tittle (1995) called a control balance as an SR moves from lower to higher levels of tenure. This also suggests that an offender can move from one type of offending (repressive) to another (autonomous) over time. As Tittle (2004) notes:

There is no necessary reason ... why a person with a control surplus would choose mainly from among 'autonomous' deviant acts. Indeed, some 'repressive' acts of deviance may be more appropriate to the level of control surplus operating in a given instance than are some of the 'autonomous' misbehaviors. Similarly, persons with a control deficit who become motivated toward deviance sometimes may be able to commit 'autonomous' deviant acts and may in fact choose them over 'repressive' forms. Hence, the continuum of seriousness probably does not break nicely in the middle of the control ratio continuum, nor does it seem to run on parallel off set tracks as the original formulation implied. In fact, ... some research has shown, control imbalances, whether surpluses or deficits, may predict all forms of deviant outcome without much differentiation by whether they are 'autonomous' or 'repressive' in nature. (p.400)

Before proceeding, note that tenure within the corporation does not differentiate one SR from another in terms of services and products available to sell, commissions, or the types of prospective customers the SR may approach. Rookie and veteran SRs are no different in that regard. But, it does affect one's knowledge of the organization and its processes, allowing more experienced (i.e., longer tenured) employees to potentially take advantage of such knowledge ${ }^{9}$. Simply put, lower tenure is more likely to result in a control deficit while higher levels of seniority are more likely to result in a control surplus.

\footnotetext{
${ }^{9}$ Experience has similar effects on how offenders operate, with greater experience affording more and better opportunities and greater chances of success in criminal activities (see Topalli, 2005; Walters, 2003)
} 
Seniority, in fact, is a key determinant of rank in the sales field (Dustmann \& Meghir, 2005; Segalla, Rouzies, Besson, \& Weitz, 2006) and offers a wider range of autonomy; a distinguishing function of a control surplus (Tittle, 1995). For example, those with higher tenure tend to have less supervision performing their duties and feel less pressure to achieve quotas. More tenured SRs have reached a higher level of experience, understanding of company systems, and the industry as a whole. Typically, they are also the ones who produce a strong revenue stream for the company. The company, therefore, tends not to interfere with their daily processes. Consequently, these SRs can exert a greater amount of control over their day-to-day activities than the company is willing to apply over them. Ironically, it is exactly because of their advanced experience and autonomy that they also know how to exploit the system (as suggested by Tittle, 1995).

Conversely, for the company that provided the data for this study, upper management confirmed that, as a matter of common practice, less tenured SRs experience high levels of supervision. As a SR's tenure with the company increases, this level of scrutiny decreases apace as they become more familiar with company sales procedures and the internal workings of its onboarding systems. This is typical of businesses that employ a sales force. According to Wright (2000), newer representatives have little to no autonomy or decision-making authority. Further, because of this status, they have limited understanding of company procedures and systems. Despite this type of control deficit, this company is not alone in applying pressure on its less tenured SRs to achieve sales goals and secure a sustainable income (Rollag, Parise, \& Cross, 2005, Segalla et al., 2006). At this career stage, the company naturally exerts greater levels of control over these newer SRs than they are able to counter. This places them squarely in a control deficit condition. Due to their inexperience, they simply lack the ability to exploit ("game") the system. CB theory dictates that when deviance occurs with these less tenured, SRs, it generally takes the form of repressive behavior. 


\section{Data}

The data used in this study originates from a large US corporation and consists of all of the investigations conducted by the company on members of the sales force from 2004 to 2012 (N=445). ${ }^{10}$ There were many more allegations of misbehavior made against the sales force. However, the cases used in the analysis were only the ones emanating from official investigations. The company's internal investigation's team, consisting of experienced specialists in risk, compliance, and law enforcement, confidentially conducted each of these investigations through forensic evidence, customer statements, publicly available information, and other internal information. Only in the face of overwhelming evidence did this team then conduct interviews with the SR(s) involved. In the majority of the investigations conducted, the SRs themselves admitted to the behaviors of which they were accused. At the conclusion of the SR interview, the investigations team marked each individual case as either valid, invalid, or inconclusive. For this study, the cases provided to us were only those deemed valid by the investigations team.

The information captured for analysis incudes demographic variables, type of sales position, and tenure in months. The dataset also provides information on the type of misconduct found such as policy and ethics violations (gaming the system) or criminal acts (forgery, theft, altering documents, etc.) committed by the SRs (see Table 1). The company graciously provided these data redacting any information that might allow for the identification of its SRs or the customers it serves.

\section{Dependent Variables}

Stated previously, we are not predicting whether deviance will occur. In fact, in this data set it has already occurred. Rather we are exploring that, when deviance does occur, the

\footnotetext{
${ }^{10}$ Note that these data represent the entire population of investigations within the corporation. Because is it not a sample, effect size is emphasized over statistical significance and inference.
} 
probability of the type of deviance - autonomous or repressive - is influenced by a control surplus or deficit, governed in this study by the variables, status (outside/inside) and tenure.

\section{Autonomous Deviance}

Tittle (1995) theorized that when a control surplus exists, should deviance take place, it will occur autonomously. He further stated this type of deviance would be prevalent in the white collar environment (2004). Having a control surplus allows an SR to exploit their circumstances by gaming the system. ${ }^{11}$ We operationalize autonomous deviance as a dependent variable, defined as the violation of existing company policy, violations of the corporate code of ethics, and violations of non-compete agreements (poaching). Violations of policy include such actions as self-dealing - selling equipment to customers on the side instead of selling company equipment thereby increasing the money to be made on a sale ${ }^{12}$ or offering corporate promotions to customers who do not qualify. Ethics violations include such behavior as false reporting of sales numbers, encouraging subordinates to commit fraud or falsify information, and other deceitful practices. Last, autonomous deviance occurs through violations of non-compete agreements with both the current SR's agreement and contracts signed with previous employers. ${ }^{13}$ Non-compete violations can also take the form of a conflict of interest (i.e. working for the corporation and its competitor at the same time). Autonomous deviance was operationalized as a dichotomous variable, collapsing the above listed behaviors, where their existence was coded as " 1 ," and otherwise coded as " 0. ."

\section{Repressive Deviance}

A control deficit condition manifests itself by defiant, predacious, or submissive deviance (Tittle, 1995). Tittle (1995) defined behavior of this nature as "repressive" types of deviance along the lines of traditional criminality. Within this dataset, the SRs who committed

\footnotetext{
${ }^{11}$ As opposed to direct criminality such as in a control deficit - repressive - state.

${ }^{12}$ Because this is done "off the books" it is also tax-free.

${ }^{13}$ Competitors of the subject corporation.
} 
repressive deviance did so through four crimes; theft, altering a contract, forgery, and rewriting an existing contract (identity theft). We define theft traditionally as "a crime in which a person intentionally and fraudulently takes ... property of another without permission ... with the intent of to convert it to the taker's use" (Garner \& Black, 2004). Theft by SRs occurred mainly by taking equipment either from the corporation or the customer through deceptive means, later converting it to cash or its equivalent.

Forging a contract was indicated when an SR submitted paperwork that purports to have been signed by the customer when, in fact, the SR signed the document as the customer. It also occurred by means of the SR adding a document to the sales agreement (that a customer did not agree to) and signing the customer's name to it, a practice referred to as "clean sheeting" (Payne, 2012). Rewriting an existing contract is another type of fraud where the SR receives multiple commissions for the same sale. In this case, the SR duplicated the original information on a new contract and resubmitted the paperwork as if it were a new customer while simultaneously closing out the old contract. SRs who engage in this scheme have retained the customer's information from the original contract, considered by law to be identity theft, and committed the crime without the customer's knowledge.

Altering a contract, considered sometimes a different type of forgery, occurred when an SR added, deleted, or changed information on the original contract without that customer's knowledge or consent, usually after the customer signed the agreement. This differs in that the customer did, in fact, sign the agreement, but particular terms of the agreement (not the signature itself) were altered after the signatures were made. SRs typically made this change for purposes of charging the unsuspecting customer and company with higher fees for services resulting in higher residual payments to the seller. Since each of the SRs receives a portion of the profits made on each transaction, altering the agreed upon fees ever so slightly 
(changing .55 cents per transaction to .88 cents per transaction) adds up to thousands of dollars stolen from the customer, and the company, over time.

Tittle $(1995,2004)$ contended that these types of deviance are the result of a control deficit condition. These crimes were also collapsed into one category, repressive deviance. We coded them as " 1 " if any of these crimes were committed and " 0 " otherwise.

\section{Independent variables}

\section{Tenure}

Tenure in the original dataset was coded as a continuous variable with each increment corresponding to one month of employment. When analyzing this variable in its original form, the data had a positive skew violating the regression normality assumption. To correct this, we performed a natural log transformation normalizing the distribution and created a new continuous variable, LN Tenure (see Figure 2). We used this new variable in the final analyses.

Figure 2: Natural Log Transformation of Months Tenure

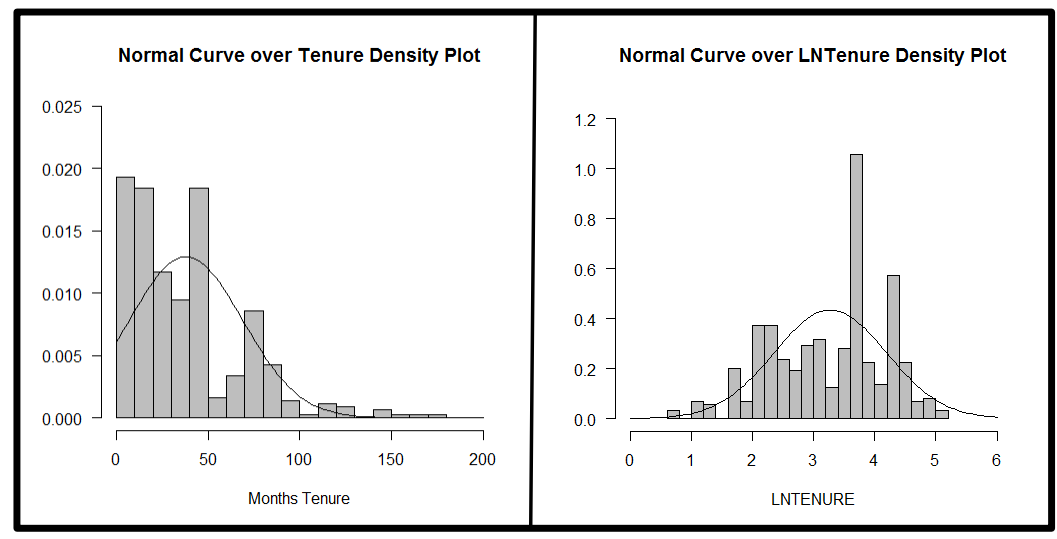

\section{Sales Position}

The sales position variable delineated the SRs occupational status. We created two variables, outside and inside, to represent this status. Assignment to an outside sales position resulted in a coding of the outside variable as a " 1 " otherwise " $0 . "$ In the same manner, a coding of "1" on the inside variable indicated a SRs assignment to the inside sales force and a " 0 " coding designated he or she was not a member of this group. Practically, these variables 
are mirrors of each other since SR assignment is either to the outside or inside sales force; however, creating these two separate variables allowed for a more intuitive interpretation of the analyses to follow.

\section{Control Variables ${ }^{14}$}

Sex

Bureau of Justice Statistics data show that males are generally more criminogenic than females (BJS, 2011). It was reasonable then to anticipate that the SR's biological sex could influence deviant behavior. Sex was consequently held constant in each of the statistical models. Males received a dichotomous coding of "1" and females a " 0 ."

\section{Age}

Research suggests that individuals aged 41 to 50 more often commit corporate fraud than any other age group. Persons over 40 commit more than half of the total number of the corporate crimes reported in the US each year (ACFE, 2008). The data also show that age is a predictor of traditional crime (FBI, 2015). As this could confound the current analysis results, our model included age as a continuous control variable.

\section{Analytical strategy}

Testing the proposed hypotheses began with a descriptive analysis summarizing the data. From a purely descriptive standpoint, Tittle's concept of a control balance and imbalance became evident in the data (see Figure 3 in the Results section). We then turned our attention toward a method to incorporate the notion of a control balance ratio in determining the type of expected deviance given the predictors contained in the dataset.

Because the outcome variables used in this study are dichotomous, binary logistic regression analysis was the most appropriate design. Not only did it account for the nonlinearity of the variables, this technique also provides the odds ratios of SR engagement in

\footnotetext{
${ }^{14}$ Race was not included because there was no variance in this unit of measurement.
} 
repressive or autonomous deviance by means of their position or tenure. ${ }^{15}$ While Tittle did not specifically propose a singular, specific analytical strategy to explicate the control balance ratio, we saw value in approximating this through the odds ratios produced when exponentiating the regression coefficient and at the same time accounting for the curvilinear shape of a control imbalance as originally described in the theory. Moreover, due to the continuous nature of the tenure predictor variable, we employed second order exponentiation on the right-hand side of the equation as a method of confirming the logistic regression results, accounting even further for the theoretical curvilinear nature of the control balance and imbalance characteristics. Finally, other non-linear regression techniques such as segmented or spline regression could not produce as good a proxy for Tittle's hypothesized ratio as they did not lend themselves as well to the data at hand.

By deploying binomial logistic regression as our primary analytical method, we specifically expected that autonomous deviance committed by SRs would occur through a control surplus afforded by either an outside sales position or advanced tenure and, correspondingly, that repressive deviance could be explained by a control deficit condition due to an inside sales position or lesser levels of tenure.

\section{RESULTS}

\section{Descriptive analysis}

Table 1 displays the results of the descriptive analysis. Autonomous deviance accounted for half of the cases $(49.4 \%, \mathrm{~N}=225)$ contained in the dataset. Ethics violations accounted for $18.2 \%(\mathrm{~N}=81)$ of the total cases. Policy violations marked $21.3 \%(\mathrm{~N}=95)$ of the cases in the dataset and non-compete violations made up $9.9 \%(\mathrm{~N}=44)$ of the investigations.

\footnotetext{
${ }^{15}$ Bivariate analyses were performed and found to be consistent with regression results. Thus, the bivariate results were excluded from this publication.
} 
Table 1: Descriptive Analysis ( $\mathrm{N}=445)$

\begin{tabular}{|cccc|}
\hline Dichotomous variables & & Frequency & Percentage \\
\hline Autonomous deviance & Yes & 220 & 49.4 \\
& No & 225 & 50.6 \\
Ethics violations & Yes & 81 & 18.2 \\
& No & 364 & 81.8 \\
Policy violations & Yes & 95 & 21.3 \\
& No & 350 & 78.7 \\
Non-compete violations & Yes & 44 & 9.9 \\
& No & 401 & 90.1 \\
Defiant deviance & Yes & 225 & 50.6 \\
& No & 220 & 49.4 \\
Forgery & Yes & 84 & 18.9 \\
& No & 361 & 81.1 \\
Rewriting a contract & Yes & 12 & 2.7 \\
& No & 433 & 97.3 \\
Altering a contract & Yes & 104 & 23.4 \\
& No & 341 & 76.6 \\
Theft & Yes & 109 & 24.5 \\
& No & 336 & 75.5 \\
Outside SR & Yes & 358 & 78.2 \\
& No & 87 & 19.6 \\
Male SR & Yes & 348 & 78.2 \\
& No & 97 & 21.8 \\
\hline Continuous variables & Mean (SD) & Min & Max \\
\hline Months tenure & $37.96(30.90)$ & 2 & 176 \\
LN months tenure & $3.27(.92)$ & 0.69 & 5.17 \\
SR age & $43.21(9.38)$ & 23 & 67 \\
\hline
\end{tabular}

Repressive deviance made up the remainder of the cases in the population $(50.6 \%$, $\mathrm{N}=220)$. Forgery cases represented $18.9 \%(\mathrm{~N}=84)$ of the population. Rewriting a contract made up $2.7 \%(\mathrm{~N}=12)$ of the cases in the study. The SRs altered contracts in $23.4 \%(\mathrm{~N}=104)$ of the cases and committed theft $24.5 \%(\mathrm{~N}=109)$ of the time.

The last two dichotomous variables were SR sales position and biological sex. The majority of the investigations involved SRs assigned to the outside sales force $(80.4 \%$, $\mathrm{N}=358)$ as opposed to the inside sales force $(19.6 \%, \mathrm{~N}=87)$. Similarly, male SRs were represented in $78.2 \%(\mathrm{~N}=348)$ of the cases versus their female counterparts $(21.8 \%, \mathrm{~N}=97)$.

There were two continuous variables in the model; tenure and age. The average SR months tenure was 37.96 months $($ S.D. $=30.90)$. Mentioned previously, this variable was positively skewed but corrected through a natural $\log (\mathrm{LN})$ transformation. Utilized in the 
final regression analyses, this new variable, LNTENURE, represented this measure $($ mean $=3.27$, S.D. $=.92)$. The second continuous variable in the analysis was the age of the SR. This variable ranged from 23 to 67 years of age averaging 43.21 years $($ S.D. $=9.38)$.

Tittle (2004) emphasized that "those with control balances are theorized to conform most of the time" (p. 397). This is the point were the ratio between the amount of control on both sides of the spectrum are essentially the same. Tittle further argued that the further a person is removed from this balance point, the higher the respective defict or surplus ratios and the greater the likely of deviant behavior $(1995,2004)$. Consistent with this notion, and confirming our original prediction (see again Figure 1), this is in fact what we encountered (see Figure 4). There is a marked dip in the level of offending where tenure is at its mid-point.

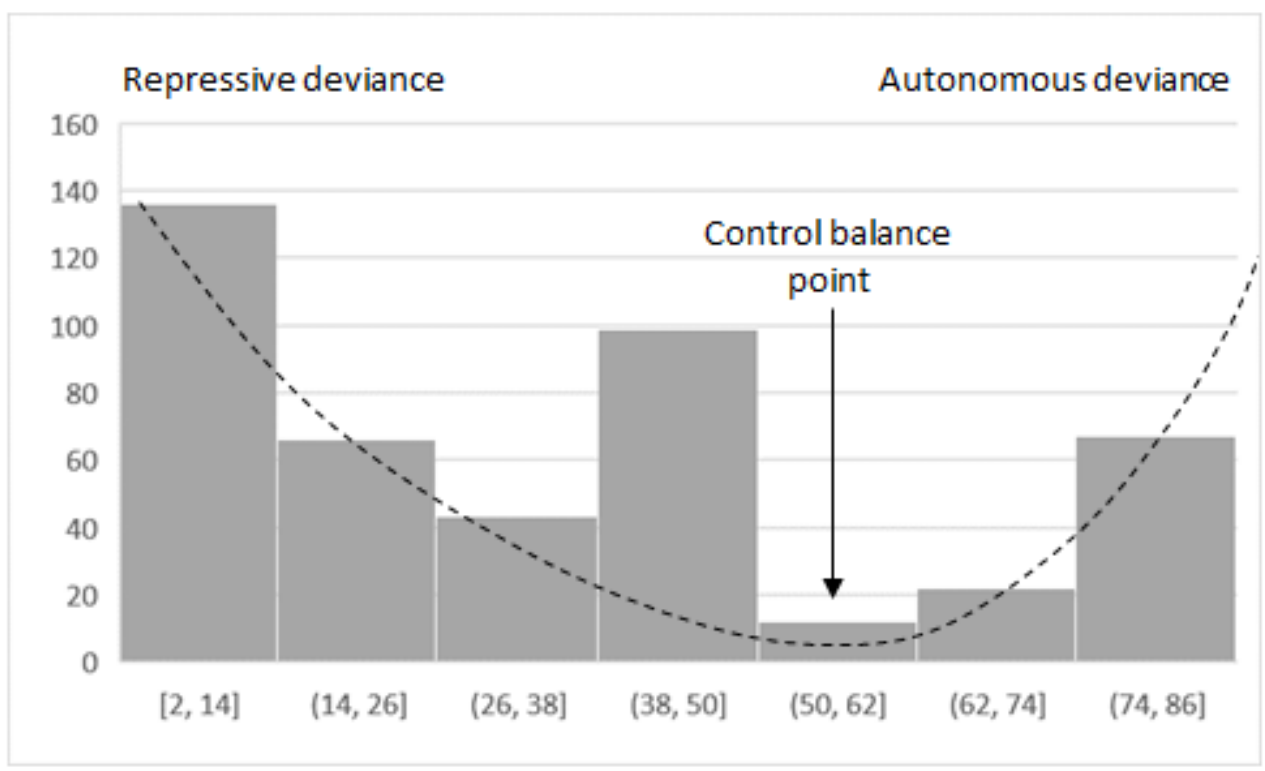

Months Tenure

Figure 4: Control Balance Point

From a purely descriptive persective, the frequencies of both repressive and autonomous deviance are highest at the extreme ends of the months tenure timeline. Closer to the center of the graph is the hypothesized and (in this study) actual balance point where deviance is at its lowest. Thus, it could be argued that the frequency of deviance displayed in 
Figure 4 offers strong support for the idea that (1) Tittle's theoretical balance point in fact exists and (2), the distance in either direction from that point acts as an indicator of the ratio of control experienced and exerted through the amount of deviance that actually occurs.

\section{Regression analyses}

\section{Hypotheses H1 a and $\mathrm{H}_{\mathrm{b}}$}

The first variable tested as a predictor of autonomous deviance was LNTENURE both by itself (Model 1) and with controls (Model 2). The results, shown in Table 2, support hypothesis $\mathrm{H}_{1 \mathrm{a}}$ that higher levels of SR months' tenure increased the odds of autonomous deviance. Formally, Model 1 employed a naïve binary logistic regression formula:

$$
g(x)=\ln \left(\frac{\pi}{1-\pi}\right)=\beta_{0}+\beta_{1} x_{L N T}
$$

where $L N T$ is the LNTENURE variable. We then calculated the odds ratio through exponentiation of its regression coefficient: $\mathrm{OR}=e^{\beta_{1}}$. Model 2 utilized a multivariate binary logistic regression analysis with LNTENURE predicting autonomous deviance but also controlling for sex, age, and sales position considering their potential ability to confound the results. The equation was such that:

$$
g(x)=\ln \left(\frac{\pi}{1-\pi}\right)=\beta_{0}+\beta_{1} x_{L N T}+\beta_{2} x_{\text {male }}+\beta_{3} x_{\text {age }}+\beta_{4} x_{\text {out }}
$$

where $L N T=\mathrm{LN}$ months' tenure, male $=1$ if the SR was male, age $=$ the age of the SR, and out $=1$ if the SR held an outside sales position. Again, the odds ratio calculation occurred through exponentiation of $\beta_{1}$.

In addition to the regression coefficients and odds ratios, Table 2 displays standard error and significance levels for each variable. This table, and in the remainder of the results tables to follow, also reports Pearson's Chi-square test of model fit and Cox and Snell's pseudo- $\mathrm{R}^{2}$ values. Experts consider the Cox and Snell pseudo- $\mathrm{R}^{2}$ calculation a more conservative estimate than, for example, Nagelkerke's $\mathrm{R}^{2}$ (Weinberg \& Abramowitz, 2008). Considering the complexities of measuring a control surplus and control deficit, we opted for 
more conservative estimates. Finally, variance inflation factor (VIF) calculations indicated no multi-collinearity among the model variables further verifying the models.

Table 2: HIa - Regressions with LNTENURE predicting Autonomous deviance $(N=445)$

\begin{tabular}{|c|c|c|c|c|c|c|}
\hline & Model 1: & LNTENUR & & Model 2: & LNTENURE & with controls \\
\hline & $\mathrm{B}(\mathrm{SE})$ & Sig. & $\operatorname{Exp}(\mathrm{B})$ & $\mathrm{B}(\mathrm{SE})$ & Sig. & $\operatorname{Exp}(B)$ \\
\hline Intercept & $-1.793(.378)$ & .000 & .166 & -1.710 & .007 & .181 \\
\hline LNTENURE & $.540(.111)$ & .000 & 1.715 & $.524(.112)$ & .000 & 1.719 \\
\hline Male & --- & --- & --- & $.089(.240)$ & .709 & 1.090 \\
\hline Age & --- & --- & --- & $-.013(.011)$ & .228 & .987 \\
\hline \multirow[t]{3}{*}{ Outside SR } & --- & --- & --- & $.484(.251)$ & .055 & 1.619 \\
\hline & Chi square $=26.26$ & $p=.000$ & $d f=443$ & Chi square $=28.6$ & $p=.000$ & $d f=4$ \\
\hline & Cox and Snell & $R^{2}=.054$ & & Cox and Snell & $R^{2}=.090$ & \\
\hline
\end{tabular}

Model 1 indicated that, without including control variables, the odds of committing autonomous deviance increase by 1.715 times with each incremental rise in months' tenure $(\mathrm{p}=.000)$. Months tenure by itself explained just over five percent of the variance in autonomous deviance $\left(\mathrm{R}^{2}=.054, \mathrm{p}=.000\right.$, chi square $\left.=26.26, \mathrm{df}=443\right)$. Model 2 estimated the effect of LNTENURE on autonomous deviance with the control variables. The results confirmed that, even when factoring in possible confounders, as tenure accumulates the odds of committing autonomous deviance are increased 1.719 times for each additional (logarithmic) month increase $(\mathrm{p}=.000)$. Therefore, because having increased tenure provides the SR with a control surplus and this same variable predicts autonomous deviance, the results support hypothesis 1a. Within the corporate sales environment, a control surplus predicts higher odds of committing autonomous deviance. Furthermore, the pseudo $\mathrm{R}^{2}$ value in Model 2 increased to 0.09 indicating that the combined variables explain nine percent of the variance in autonomous deviance. While this pseudo $\mathrm{R}^{2}$ level is not particularly high, it is consistent with prior analyses supporting CB theory (Piquero \& Hickman, 2003; Piquero \& Piquero, 2006; Higgins et al., 2004). 
Models 3 and 4, tested hypothesis $1 \mathrm{~b}$ which stated that lower levels of corporate tenure place an SR at higher odds of repressive deviance through a control deficit. Table 3 lists these results. Repressive deviance - autonomous deviance's dichotomous mirror - was regressed on LNTENURE using the same type of equation in this first analysis. Model 3 shows the results of repressive deviance regressed on LNTENURE with no controls. Considering only these two variables, the negative coefficient $(B=-0.540)$ indicates that as tenure increases, the odds of committing repressive deviance decreases. In fact, the odds ratio is halved with every increase $(\operatorname{Exp}(B)=.542) .{ }^{16}$ Since less tenured SRs are in a control deficit condition, it follows that they would indeed engage more often in repressive behavior but as tenure increases, the control deficit gives way to a control surplus and so too the odds of committing repressive deviance decrease having been replaced with autonomous behavior through understanding of company systems.

Model 4 as in Model 2, also held constant the SR's age, biological sex, and sales position.

Table 3: H1b - Regressions with LNTENURE predicting Repressive deviance $(N=445)$

\begin{tabular}{|c|c|c|c|c|c|c|}
\hline & Model 3: & LNTENURI & & Model 4: & LNTENURE & with controls \\
\hline & $\mathrm{B}(\mathrm{SE})$ & Sig. & $\operatorname{Exp}(B)$ & $\mathrm{B}(\mathrm{SE})$ & Sig. & $\operatorname{Exp}(B)$ \\
\hline Intercept & $1.793(.378)$ & .000 & 5.99 & $1.225(.589)$ & .037 & 3.404 \\
\hline LNTENURE & $-0.540(.111)$ & .000 & .583 & $-.542(.112)$ & .000 & .582 \\
\hline Male & --- & --- & --- & $-.090(.240)$ & .710 & .407 \\
\hline Age & --- & --- & --- & $.013(.011)$ & .228 & 1.013 \\
\hline Inside SR & --- & --- & --- & $.481(.251)$ & .055 & 1.617 \\
\hline & Chi square $=25.35$ & $p=.000$ & $d f=444$ & Chi square $=25.35$ & $p=.000$ & $d f=4$ \\
\hline & Cox and Snell & $R^{2}=.041$ & & Cox and Snell & $R^{2}=.050$ & \\
\hline
\end{tabular}

\footnotetext{
${ }^{16}$ Put another way, as tenure decreases, the odds of committing repressive deviance are increased.
} 
The results demonstrate that as SR tenure increases the odds of committing repressive deviance significantly decrease $(\operatorname{Exp}(B)=-.542, p=.000)$. These results indicate that lower tenured SRs are at higher odds of committing repressive deviance supporting hypothesis $1 \mathrm{~b}$. Because these same individuals are subject to a control deficit, Tittle's $(1995,2004)$ concepts behaved, again as predicted.

\section{Hypotheses $\mathrm{H} 2_{\mathrm{a}}$ and $\mathrm{H} 2_{\mathrm{b}}$}

The second hypothesis stated an SR would also commit deviance by means of the control surpluses and deficits inherent to the type of sales position (status) they occupy. The results shown in Table 4 support this supposition. Hypothesis $2 \mathrm{a}$ theorized that having an outside sales position provides an SR with a control surplus increasing the odds of committing autonomous deviance. Model 5 tested this hypothesis by first regressing autonomous deviance on an outside sales position alone. Model 6 then tested this with control variables.

Table 4: H2a - Regressions with outside sales position predicting autonomous deviance (N=445)

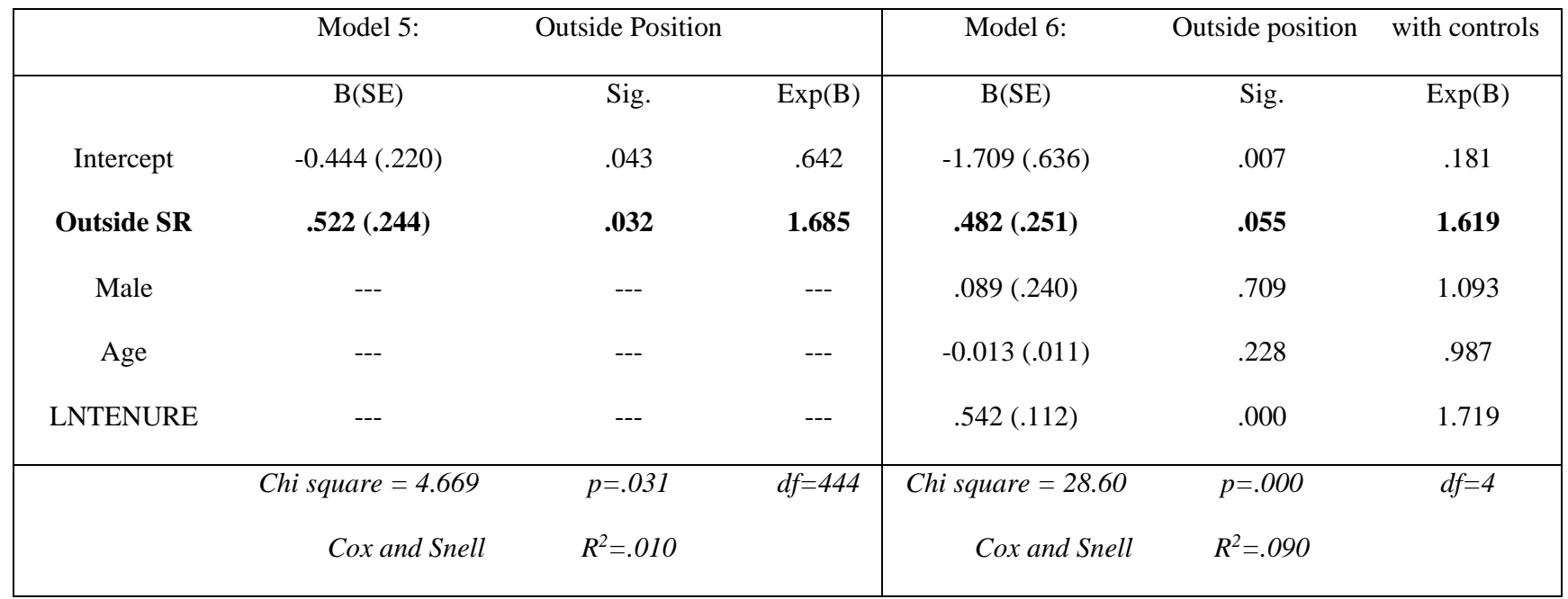

Because of the dichotomous coding of the outcome and most of the predictor variables, the results in Model 6 echo Model 2. The formula and results remain the same but are arranged in different order to reflect the switch of the outside variable from control to predictor and vice versa for LNTENURE: 


$$
g(x)=\ln \left(\frac{\pi}{1-\pi}\right)=\beta_{0}+\beta_{1} x_{\text {out }}+\beta_{2} x_{\text {male }}+\beta_{3} x_{\text {age }}+\beta_{4} x_{L N T}
$$

In Model 5, outside SRs were found to have 1.685 times higher odds of committing autonomous deviance than their inside SR counterparts $(p=0.032)$ without control variables. When adding the controls (Model 6), the findings show that outside SRs are at 1.619 times higher odds of committing autonomous deviance $(\mathrm{p}=.055) .{ }^{17}$ These results indicate that if an SR can exert more control over the way he or she conducts business than the corporation can exert back, as an outside SR is able to do, this significantly increases the odds of autonomous deviance.

Hypothesis $2 b$ stated that inside SRs are at greater odds of committing repressive deviance due to a control deficit through occupational status. The regression results, displayed in Table 5, confirm this hypothesis. Model 7 illustrates the direct effect of an inside sales position on repressive deviance without controls. By itself, having an inside sales position increases the odds of committing repressive deviance by a factor of 1.686 times $(\mathrm{p}=.032)$. Model 8 shows the results when the control variables are included in the equation. The findings in Model 8 are also supportive of the hypothesis. The odds of an inside SR engaging in repressive deviance were 1.617 times that of an outside SR. Since inside SRs typically experience a control deficit, once more, the model behaved according to Tittle's (1995) concepts. $^{18}$

\footnotetext{
${ }^{17}$ Although the p-value is slightly outside the range of an alpha level of $<.05$, again it is stressed that the data utilized is a population and describing the effect size is the more appropriate interpretation.

${ }^{18}$ Although not considered in the original formulation of our hypotheses, the question then arose that, if an outside SR is more likely to commit acts of exploitative deviance and that a more tenured SR is at greater odds of engaging in this same behavior, would the effect size increase if a tenured SR were a member of the outside sales force? If so, would the same be true for a less tenured SR assigned to an inside sales position committing repressive deviance? Cross product analysis showed this not to be the case. In both cases, the effect size dropped and the interactions were far above the accepted $\mathrm{p}<.05$ standard.
} 
Table 5: H2b - Regressions with inside sales position predicting repressive deviance $(N=445)$

\begin{tabular}{|c|c|c|c|c|c|c|}
\hline & Model 7: & Inside position & & Model 8: & Inside position & with controls \\
\hline & $\mathrm{B}(\mathrm{SE})$ & Sig. & $\operatorname{Exp}(\mathrm{B})$ & $\mathrm{B}(\mathrm{SE})$ & Sig. & $\operatorname{Exp}(B)$ \\
\hline Intercept & $-0.078(.106)$ & .460 & .925 & $1.225(.589)$ & .037 & 3.404 \\
\hline Inside SR & $.522(.244)$ & .032 & 1.686 & $.482(.251)$ & .055 & 1.617 \\
\hline Male & --- & --- & --- & $-.090(.240)$ & .710 & .407 \\
\hline Age & --- & --- & -- & $.013(.011)$ & .228 & 1.013 \\
\hline \multirow[t]{3}{*}{ LNTENURE } & --- & --- & -- & $-.541(.112)$ & .000 & .582 \\
\hline & Chi square $=4.669$ & $p=.031$ & $d f=444$ & Chi square $=28.60$ & $p=.000$ & $d f=4$ \\
\hline & Cox and Snell & $R^{2}=.010$ & & Cox and Snell & $R^{2}=.090$ & \\
\hline
\end{tabular}

In general, though, while sales position predisposes an SR to certain types of deviance there is no guarantee that form of deviance will occur. In fact, the data showed there were outside SRs that engaged in the types of behavior predicted for an inside SR and vice versa. The results of these analyses consequently demonstrate that the nature of a sales position simply provides individuals occupying that status with a "head start" to engage in the predicted type of deviance. In effect, if sales position were the only measure of control, SRs would experience either a surplus or deficit with no middle ground (i.e. balance). Because of the dichotomous nature of sales position (inside/outside: deficit/surplus), the control balance mid-point that Tittle emphasizes could not ever be manifested analytically. Yet, in this study, tenure also plays a crucial role, one that sheds light into this concept of balance due to its continuous in nature.

Regression results showed that tenure predicted a particular type of deviance but on a sliding scale: Low levels predicted repressive deviance but as tenure incrementally increased so too the odds of autonomous deviance. These results offer an empirical glimpse into Tittle's theoretical balance point. While a SRs status conditions a person to a particular type of deviance, tenure tends to play the key role in the deviance. For instance, a newly hired SR 
assigned to the outside sales force has a control surplus through position, normally a status conditioning autonomous deviance. Yet that individual's tenure has not yet reached a level where that autonomy becomes a tool toward deviance. Consequently, while the working conditions of an outside SR predispose them to autonomous deviance through a control surplus, the fact that they are new to the company may cause them to fall back on more traditional (repressive) types of criminality until familiarity with the system allows for autonomous deviance. We suggest then that tenure, with its incremental nature, is the underlying vehicle toward imbalances and balances within the sales force. The more influential piece of the deviance equation, thus, is tenure due to its continuous, incremental nature.

Tables 2 and 3 illustrate that when an SR is first hired the odds of engaging in repressive deviance are high, yet as time passes the odds of autonomous deviance increase by a factor of 1.719 times for each additional increment of tenure. In contrast, outside SRs are at 1.619 times higher odds of committing autonomous deviance as opposed to their inside SR counterparts. The odds ratios resulting from these regressions, in fact, confirm (and clarify) Tittle's original notion that a control imbalance is arrayed continuously as fractions or proportions (1995, p. 161). More importantly, these results make tenure the more contributory influence because of its incremental nature. Low levels of tenure are synonymous with low levels of experience and are more likely to produce repressive deviance. As tenure increases, the odds of repressive deviance decrease, and are eventually surpassed by the odds of autonomous deviance occurring.

Given these results, that the odds ratio of an outside SR committing autonomous deviance was 1.619 times more than that of an inside SR and that the odds ratio of committing autonomous deviance increase by 1.719 times for each months' tenure, it is important to then determine whether the odds ratio would be higher for an outside SR with advanced tenure. 
The results depicted in Table 4 illustrate that this was, in fact, the case. By creating an interaction term consisting of position times tenure and regressing deviance on this new variable, we were able to make a determination as to this question. The odds of a tenured outside SR committing autonomous deviance increased 1.758 times with each month employed with the company. While only slightly higher than the direct effect of tenure (1.719) and a little more than the direct effect of sales position (1.619), the interaction of both these conditions does increase the odds ratio incrementally.

Table 4: Interaction regression results of outside $x$ tenure $(N=445)$

\begin{tabular}{|cccc|ccc|}
\hline & Model 1: & Exploitative & \multicolumn{2}{c|}{ Model 2: } & \multicolumn{2}{c|}{ Exploitative with controls } \\
\hline & B(SE) & Sig. & Exp $(\mathrm{B})$ & B $(\mathrm{SE})$ & Sig. & $\operatorname{Exp}(\mathrm{B})$ \\
Intercept & $-0.035(0.097)$ & 0.720 & 0.966 & $0.514(0.494)$ & 0.298 & 1.672 \\
INTERACTION & $\mathbf{0 . 5 5 5 ( \mathbf { 0 . 1 2 1 } )}$ & $\mathbf{. 0 0 0}$ & $\mathbf{1 . 7 4 2}$ & $\mathbf{0 . 5 6 5}(\mathbf{0 . 1 2 2})$ & $\mathbf{. 0 0 0}$ & $\mathbf{1 . 7 5 8}$ \\
Male & --- & --- & --- & $0.1(0.237)$ & 0.686 & 1.101 \\
Age & --- & --- & --- & $-0.015(0.010)$ & 0.167 & 0.99 \\
\hline & Chi Square $=27.05$ & $p=.000$ & $d f=444$ & Chi Square $=31.11$ & $p=.000$ & $d f=441$ \\
& Cox and Snell & $R^{2}=0.055$ & & Cox and Snell & $R^{2}=.092$ & \\
\hline
\end{tabular}

While the logit function in the logistic regressions converts the non-linear binomial "scurve" to a more linear shape, exponentiating the beta values to attain an odds ratio produced the value in which we were most interested, regardless of linearity/non-linearity. As a final step in accounting for what Tittle hypothesized as a non-linear (exponential) relationship between the types of deviant behavior relative to the strength of the control imbalance, we squared the sales position and tenure predictor variables and re-ran the regressions to produce the quadratic results. In each case the odds ratios for autonomous deviance remained significant and decreased only slightly $\left(\right.$ Tenure $=1.16^{* * *}$, Outside sales position $=1.58^{* * *}$, Interaction $=1.11 * * *)$.

\section{DISCUSSION}

Recall that Tittle's (1995) control balance $(C B)$ theory accounts for variation in deviance by introducing the notion that control factors should be represented as the ratio of the level of control a person can exert versus the level of control they experience. CB theory 
postulates that the probability of deviance will increase as control ratios become unbalanced. When the control that an individual has over their environment and others is greater than the control exerted on them, the nature of this deviance will be autonomous: Individuals will take advantage of their position and access to resources to better their situation. However, when the control that an individual has over his environment and others is less than the control exerted on them, the nature of this deviance will be repressive: Individuals limited by their access to resources and opportunities will respond with more traditional forms of instrumental deviance.

CB theory's strength lies in its ability to account for the effect of variable levels of control (Tittle, 1995) and its consideration of desire for control (Piquero, Schoepfer, \& Langton, 2008), Tittle, 2004) as a motivator in and of itself. Importantly, it also accounts for both white collar and street deviance, and thus is one of the few theories designed to consider all deviance/offending in a unified manner. In practice, the theory has not often been applied as Tittle intended. Though CB theory was meant to address all types of crime, it has been overwhelmingly applied to explain traditional rather than white collar deviance (Piquero \& Hickman, 1999, 2003; Hickman \& Piquero, 2001; Hickman, Piquero, Lawton, \& Greene, 2001; Higgins \& Lauterbach, 2004; Higgins, Lauterbach, \& Tewksbury, 2005). The theory's key weakness however, has lied in its testability. Its propositions are complex and it conceptualizes variables whose functions operate interdependently and require simultaneous consideration in a comprehensive test. Thus, previous research testing CB theory has been sparse, limited by available data most often focused on traditional crime. Consequently, when it has taken place, the majority seems to have been more on parts of the theory rather than the whole (see e.g., Piquero \& Hickman, 1999, 2003; Hickman \& Piquero, 2001; Hickman, Piquero, Lawton, \& Greene, 2001; Higgins \& Lauterbach, 2004; Higgins, Lauterbach, \& 
Tewksbury, 2005) although a few studies do encompass its entirety (see e.g., Baron \& Forde, 2007; DeLisi \& Hochstetler, 2002).

For these reasons, we sought to expand the test of CB theory by employing a data set containing a population made up of different but related groups of white collar offenders experiencing varying levels of control and able to exert varying levels of control. Moreover, the ratios of control exerted versus control experienced by these groups was systematic according to the individual's position within the company. Our data are drawn from individuals with greater control over their settings because of their tenure within the company (shorter vs. longer) and because of their access to different kinds of criminal opportunities as facilitated by status (sales people working internally having restricted opportunities while those working off-site have more discretion).

Employing this sample of actual cases of sales representative (SR) deviance, we hypothesized specific types and likelihoods of deviance. Related to tenure within the company, (1) those with longer tenure with the corporation are at higher odds of committing autonomous deviance, while (2) those with lesser tenure are at higher odds of committing repressive deviance. Likewise, related to status of the individual (3) those in an outside sales position are at higher odds of committing autonomous deviance and, (4) those in an inside sales position are at greater odds of committing repressive deviance. In each case, the evidence supported these hypotheses. At least in this corporate sales environment, Tittle's CB theory explained both autonomous and repressive deviance. Analysis showed that having advanced tenure allows SRs to exert a higher level of control over the system than organizational controls can apply on them, resulting in autonomous deviance (see Table 2). Similarly, the newer an SR was to the corporation the more control the company had over their activities, which predicted higher odds of repressive deviance (see Table 3). The second hypothesis assumes that sales position (inside vs. outside) is associated with an invariable 
amount of control. Outside sales forces are assumed to inherently provide the individual with a control surplus, while inside SRs were subject to control deficits. The first part of this hypothesis suggested that an outside sales position afforded an SR a control surplus subsequently increasing the odds of autonomous deviance. Outside SR were, in fact, found at 1.619 times the odds of committing autonomous deviance compared to their inside sales counterparts. Reflectively, through a control deficit, members of the inside sales force had 1.617 times the odds of committing repressive deviance in opposition to outside SRs. Again, Tittle's (1995) concepts held true.

\section{Implications for control balance theory}

These findings have important implications for CB theory. To begin, as Tittle (1995, 2004) predicted, it is an especially useful theory by which to evaluate deviance in a white collar environment. In effect, the state of a person's imbalance predicts the type of deviance in which the individual will engage. Yet, this analysis presents deeper implications for CB theory. The findings confirm Tittle's contention that the motivation for deviance is different for autonomous versus repressive deviance.

Consider that a control deficit occurs because an entity (in this case the company) is exerting greater control over a person than that individual is able to counter. Consider further that one of the forms of deviance resulting from a control deficit is defiance. Thus, it can be surmised that the source of motivation for this deviance originates with the entity exerting the greater control; the source in this case being the corporation. The same principle holds for a control surplus. The source of greater control here is the individual because they have more control over the company. Since the individual is more in control, it follows that the source of the motivation to commit deviance originates from that person.

In light of our results, when deviance is present the associated motivation for that behavior shifts depending on the source of control, suggesting a dynamic process. The 
analysis of sales position - outside versus inside - illustrated this in the form of a dichotomy. However, by virtue of our results demonstrating tenure predicted deviance, motivation appears to function continuously rather than discretely. Since tenure is an incremental variable ${ }^{19}$ where lower amounts predict repressive deviance and higher levels forecast autonomous deviance, control, from a practical standpoint, must therefore be incremental. The data show that, through company tenure from the first through last days, a SR goes from an extreme control deficit where motivation originates completely from a non-internal source to an extreme control surplus where the motivation source is wholly internal. As the control ratio favors one condition- surplus or deficit - the motivation source slides along the same axis simultaneously (see Figure 3).

Figure 3: Motivation as a function of balance and source.

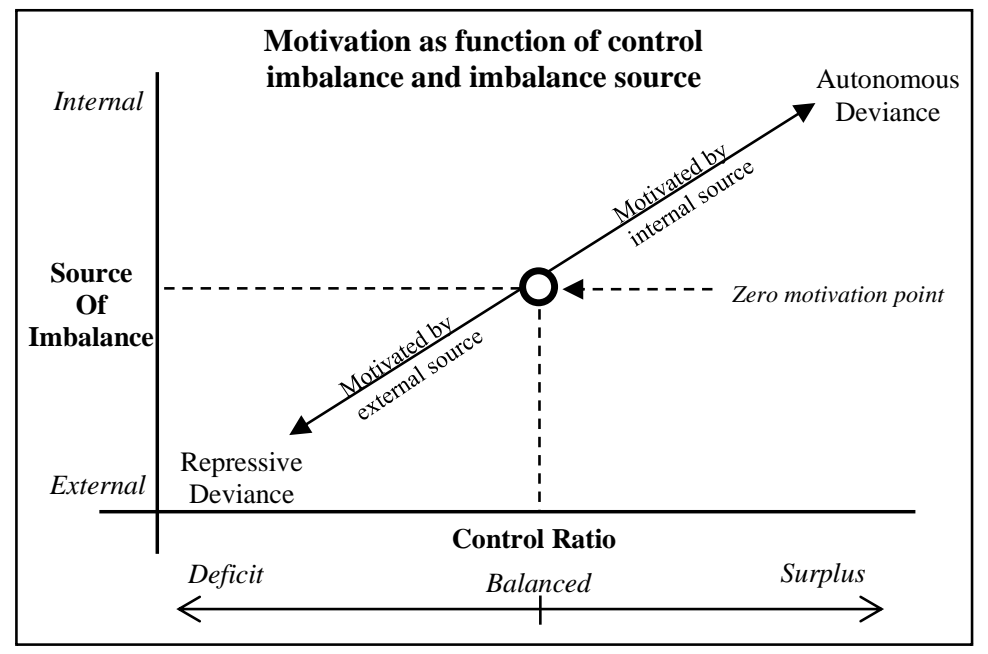

Deviance motivation, therefore, is now a function of the change in control relative to the change in the source of that control. So, the type of deviance observed shifts as the motivation changes due to the type of control imbalance and the relative source of that imbalance. In this study, this indeed appears to be the case as lower levels of tenure place SRs in a control deficit condition. Because the company is clearly exerting more control over the new SR

\footnotetext{
${ }^{19}$ Technically from $0-\infty$
} 
(especially in extremely low levels of tenure), that external pressure appears to be the impetus that motivates the repressive behavior. The results also indicate the reverse to be true with high levels of tenure.

A critical aspect of this study involves the use of two variables - one dichotomous and the other continuous - to make predictions about the likelihood and type of deviance in which individuals will engage. While potential issues to do with combining such variables in one analysis have been dealt with in the results section, the conceptual implications are considered here. SR status operates in many ways as an organismic variable. One cannot operate with both statuses (inside or outside) at the same time, and each type of status is imbued with a certain level of control. What does this mean for the theory's prediction of deviance?

In the present study we found a main effect of status in the predicted direction. Outside SRs had higher probabilities of engaging in autonomous deviance while inside SRs had higher probabilities of engaging in repressive deviance. It is important to make clear however, that this does not mean that outside SRs do not engage in repressive deviance or that inside SRs do not engage in autonomous deviance. They can and sometimes do, as Tittle (1995) again predicted. It is here that we see the importance of tenure. Our analysis demonstrated a main effect of this variable such that greater levels of tenure were associated with higher levels of autonomous deviance, and lower tenure with higher levels of repressive deviance. The interaction of tenure and status in our analysis demonstrates that the probabilities of either type of deviance are more heavily influenced by tenure. This makes sense if one considers that tenure serves as a proxy for experience and knowledge of how an organizations systems work and can be exploited. While status may offer access to such systems, tenure provides an understanding of how one can exploit such access.

Thus, while an outside salesperson is inherently more likely to engage in autonomous deviance, their ability to do so will be limited by tenure. In this case, one can imagine an 
outside SR on the first day of the job having a lower likelihood of engaging in autonomous deviance than an inside SR with 20 years on the job. As time passes, though, the outside person will gain tenure and eventually surpass the inside SR in the likelihood of engaging in autonomous deviance because their accumulating tenure will increasingly allow them to take advantage of their outside status. Likewise, a long-tenured outside salesperson, though far more likely to engage in autonomous deviance will probably also be more capable of engaging in repressive deviance than a newly hired inside SR. This argument is strengthened when we consider that in this corporate setting inside and outside status are not dependent on tenure. Because people do not transition from inside to outside status (or vice versa) as a consequence of tenure in this corporation we were able to explore the functioning of tenure and status separately and in concert.

Though this study showed support for some of the root concepts found in CB theory it is not without limitations. The primary limitation was that this study assumed months' tenure and position are valid measurements for a control surplus and deficit. Braithwaite (1997) and Jensen (1999) both contended that CB theory concepts are difficult to operationalize. ${ }^{20}$ Even Tittle (2004) agreed. Yet, despite this difficulty, the measurements of both a control surplus and a control deficit yielded findings consistent with Tittle's predictions. Secondary validation of this measurement is reminiscent of Piquero and Piquero's (2006) vignette finding that a management position (those with higher tenure) predicts autonomous deviance. Additionally, this study also assumed a control imbalance condition can exist within an individual and act as a motivator. Although the empirical results indicate that a control imbalance can be present in the form of a control surplus or deficit, and further appear to act as an influence on deviance, the SRs in this study were not available for interviews that could have confirmed and contextualized this. Had we been able to speak with them, the question of

\footnotetext{
${ }^{20}$ Even Tittle (2004) acknowledged there was much ambiguity in some of the key concepts.
} 
whether or not an imbalance existed and was the driver of such deviance would have been more definitively answered. With the addition of a qualitative overlay, it is expected that the findings could be validated and made stronger.

Based on both these limitations and findings, few would argue that future CB research might be strengthened in the future through a mixed methods approach combining quantitative data of the type we use here with qualitative interviews of those represented in that data. Such an approach would allow for researchers to confirm statistically that the predicted relationships exist while at the same time allowing us to better understand deviant motivation and its source. Our work here represents a preliminary step in this direction by employing data comprised of confirmed offenders.

Doing so, allowed us to think about how such a restriction is accommodated by the theory. We alluded to this in the introduction. In Tittle's original thesis he postulates that where control expressed and experienced is equal, there will be no deviance. We illustrate this as a zero motivation point (see again, Figure 3). When a person is control-balanced, there is equilibrium between the sources of imbalance (that of the individual and that external to the individual, the company in this case). At the intersection of these two points, an individual should not be motivated to engage in deviant behavior. But, putting aside this theoretical assumption, we know that sometimes people who are at balance do deviate ${ }^{21}$. We also know that people who experience control deficits sometimes engage in autonomous deviance (e.g., the low level clerk who discovers a way to embezzle thousands of dollars from the company $^{22}$ ). Likewise, people who experience control surpluses engage in repressive deviance (e.g., the company manager who leaks embarrassing company information on the

\footnotetext{
${ }^{21}$ In Topalli and Wright (2013) for example, street offenders who had just committed offenses had the money and drugs that they desired, and thus, no reason to offend, but still did when opportunities were too attractive to ignore.

${ }^{22} \mathrm{http}: / / \mathrm{www} . d e v o n l i v e . c o m / d i s g r u n t l e d-c l e r k-t o o k-r e v e n g e-e x e t e r-b o s s e s-20 \mathrm{k} /$ story-21448236detail/story.html
} 
internet to punish the $\mathrm{CEO}^{23}$ ). Thus, the prediction would be that in a sample comprised entirely of offenders, we would not (by definition) have non-offending, but we would have the lowest level of offending where those offenders were experiencing balance.

Our exploration of $\mathrm{CB}$ theory using these data suggests that further exploration of the theory is warranted. This is based in part on the operationalization of the two independent variables of focus in our analysis, but also with the understanding that this theory requires more comprehensive data. First, the dichotomous variable, Position Status (inside vs. outside) may seem relatively stable in that employees are not randomly assigned to either status and cannot hold both statuses simultaneously. However, one can, across time, be assigned to one status for a while and the other at a later point, either within the same company (reassigned from outside SR to inside SR for example) or from one company to another (inside SR for company A then outside for company B when the employee changes jobs). As such, the variable operates as a situational - and thus, dynamic - variable. If the theory's postulates hold true, then change in status should be associated with a change in type of offending. Here, we would require data that follows individuals across time, keeping track of their career paths. Such longitudinal data are in keeping with the traditions of the life-course perspective (see Simpson, 2013; Farrington, 2003; Hagan \& Palloni, 1988; Hagan and Albonetti, 1988), but here we are talking about a "career-course" perspective. Though a complex challenge, one way to potentially obtain such data would be to merge employment records from online career websites (such as LinkedIn.com) with corporate investigation data. Moreover, different kinds of roles and statuses within a company offer access to different kinds of offending. Because status is bestowed upon the individual by the entity exercising control (the company), studies that vary the assignment of status to employees would tell us a great deal about the mechanisms that underpin how control exercised on the potential offender operate. One

\footnotetext{
${ }^{23} \mathrm{http}: / /$ variety.com/2017/biz/news/snapchat-evan-spiegel-only-for-rich-people-anthony-pompliano1202028526/
} 
intriguing notion is that because change in status is a sudden discrete event it may operate like a knifing off (Maruna \& Roy, 2007) or transition point (Laub \& Sampson, 2003) offering further opportunity to mesh notions of the life-course perspective with CB theory.

Second, because the variable Tenure operates as a continuous variable, where the source of control derives from the offender's accumulating experience. There are many ways to conceptualize and operationalize this experience; their level of familiarity with the systems of the company by virtue of time with the company, their time within a particular branch or unit of the company, their time within a given position type, regardless of company, etc. These forms of experience are all related to one another to some extent, but one can imagine situations where moving from one company to another, between units at the company, or from one role to another, would serve to shift the potential offender's level of imbalance and thereby the type and rate of offending. Again, addressing such questions requires a different kind of data to be obtained, consistent with those employed with life-course perspectives. In applying $\mathrm{CB}$ theory to explain deviance in the workplace, we would argue it is important to include both status and tenure variables as critical to explaining patterns of offending. 


\section{References}

ACFE (2008). Profiling a white collar criminal: Gender, age, and job role among key factors in occupational fraud, ACFE finds. Retrieved from http://www.acfe.com/pressrelease $\operatorname{aspx}$ ? $\mathrm{id}=4294968561$

Baron, S. W., \& Forde, D. R. (2007). Street youth crime: A test of control balance theory. Justice Quarterly, 24, 335-355.

Benson, M. L. (1985). Denying the guilty mind: Accounting for involvement in white collar crime. Criminology, 23, 583-607.

Benson, M. L., \& Moore, E. (1992). Are white collar and common offenders the same? An empirical and theoretical critique of a recently proposed general theory of crime. Journal of Research in Crime and Delinquency, 29, 251-272.

Benson, M. L., Madensen, T. D., \& Eck, J. E. (2009). White collar crime from an opportunity perspective (pp. 175-193). Springer New York.

Braithwaite, J. (1985). White collar crime. Annual Review of Sociology, 11(1), 1-25.

Braithwaite, J. (1997). Charles Tittle's control balance and criminological theory. Theoretical Criminology, 1, 77-97.

Clarke, R. V. G. (1997) Situational crime prevention: Successful case studies ( $2^{\text {nd }}$ ed.). Harrow \& Heston.

Coleman, J. W. (1987). Toward an integrated theory of white collar crime. American Journal of Sociology, 406-439.

Coleman, J. W. (2005). The criminal elite: Understanding white collar crime. Macmillan.

Cressey, D. R. (2012). Delinquency, crime and differential association. Springer Science \& Business Media.

DeLisi, M. \& Hochstetler, A.L. (2002). An exploratory assessment of Tittle's control balance theory: Results from the National Youth Survey. The Justice Professional, 15, 261272.

Dustmann, C., \& Meghir, C. (2005). Wages, experience, and seniority. The Review of Economic Studies, 72, 77-108.

Farrington, D. P. (2003). Developmental and life-course criminology: Key theoretical and empirical issues - the Sutherland Award Address. Criminology, 41, 221-225.

Federal Bureau of Investigation. (2015) FBI releases 2014 crime statistics from the national incident-based reporting system. Retrieved from https://www.fbi.gov/news/pressrel/press-releases/fbi-releases-2014-crime-statisticsfrom-the-national-incident-based-reporting-system 
Friedrichs, D. O. (2002). Occupational crime, occupational deviance, and workplace crime. Criminology and Criminal Justice, 2, 243-256.

Friedrichs, D. (2009). Trusted criminals: White collar crime in contemporary society. Cengage Learning.

Geis, G. (1991). White Collar Crime - What is it? Current Issues in Criminal Justice, 3, 924.

Geis, G. (1993). White collar crime. Sage Periodicals Press.

Geis, G. (2000). On the absence of self-control as the basis for a general theory of crime. Theoretical Criminology, 4, 35-53.

Graber, D. A. (1980). Crime news and the public. New York: Praeger.

Garner, B. A., \& Black, H. C. (2004). Black's law dictionary. St. Paul, MN: Thomson/West.

Gottfredson, M. \& Hirschi, T. (1990). A General Theory of Crime. Stanford, CA: Stanford University Press

Green, G. (1997 [1990]). Occupational Crime. Chicago, IL: Nelson-Hall Publishers.

Hagan, J., \& Albonetti, C. (1988). Structural criminology. Cambridge: Polity.

Hagan, J., \& Palloni, A. (1988). Crimes as social events in the life course: Reconceiving a criminological controversy. Criminology, 26, 87-100.

Hickman, M., \& Piquero, A. (2001). Exploring the relationships between gender, control balance, and deviance. Deviant Behavior: An Interdisciplinary Journal, 22, 323-351.

Hickman, M., Piquero, A.R., Lawton, B.A., \& Greene, J.R. (2001). Applying Tittle's control balance theory to police deviance. Policing 24, 497-519.

Higgins, G.E. \& Lauterbach, C. (2004). Control balance theory and exploitation: An examination of contingencies. Criminal Justice Studies, 17, 291-310.

Higgins, G. E., Lauterbach, C., \& Tewksbury, R. (2005). Control balance theory and violence: An examination of contingencies. Sociological Focus, 38, 241-260.

Hirschi, T., \& Gottfredson, M. (1987). Causes of white collar crime. Criminology, 25, 949974.

Jacques, S. (2014). The quantitative-qualitative divide in criminology: A theory of ideas' importance, attractiveness, and publication. Theoretical Criminology, 18, 317-334.

Jensen, G. A. (1999). A critique of control balance theory: Digging into details. Theoretical Criminology, 3, 339-343. 
Klenowski, P. M., Copes, H., \& Mullins, C. W. (2011). Gender, identity, and accounts: How white collar offenders do gender when making sense of their crimes. Justice Quarterly, 28, 46-69.

Kownatzki, M., Walter, J., Floyd, S. W., \& Lechner, C. (2013). Corporate control and the speed of strategic business unit decision making. Academy of Management Journal, $56,1295-1324$.

Laub, J. H., \& Sampson, R. J. (2003). Shared beginnings, divergent lives: Delinquent boys to age 70. Cambridge, MA: Harvard University Press.

Maruna, S., \& Roy, K. (2007). Amputation or reconstruction? Notes on the concept of "knifing off' and desistance from crime. Journal of Contemporary Criminal Justice, 23, 104-124.

Nobles, M.R., \& Fox, K.A. (2013). Assessing stalking behaviors in a control balance theory framework. Criminal Justice and Behavior, 40, 737-762.

Payne, B. K. (2012). White collar crime: A text reader. Thousand Oaks, CA: Sage Publications Inc.

Piquero, A. R., \& Hickman, M. (1999). An empirical test of Tittle's control balance theory. Criminology 37, 319-341.

Piquero, A. R., \& Hickman, M. (2003). Extending Tittle's control balance theory to account for victimization. Criminal Justice and Behavior, 30, 282-301.

Piquero, M.H.A. (2001). Exploring the relationships between gender, control balance, and deviance. Deviant Behavior, 22, 323-351.

Piquero, N. L., \& Piquero, A. R. (2006). Control balance and autonomous corporate crime. Criminology, 44, 397-420.

Piquero, N. L., Schoepfer, A., \& Langton, L. (2008). Completely out of control or the desire to be in complete control? How low self-control and the desire for control relate to corporate offending. Crime and Delinquency, 56, 627-647.

Piquero, N. L., Tibbetts, S. G., \& Blankenship, M. B. (2005). Examining the role of differential association and techniques of neutralization in explaining corporate crime. Deviant Behavior, 26, 159-188

Pratt, T. C., \& Cullen, F. T. (2000). Empirical Status of Gottfredson and Hirschi's General Theory of Crime: A Meta-Analysis, The. Criminology, 38, 931.

Reiman, J., \& Leighton, P. (2012). The rich get richer and the poor get prison: Ideology, crime, and criminal justice. New York, NY: Routledge.

Richman, D. C. (2012). Federal white collar sentencing in the United States-A work in progress. Columbia Public Law Research Paper, (12-295). 
Rollag, K., Parise, S., \& Cross, R. (2005). Getting new hires up to speed quickly. MIT Sloan Management Review, 46, 35-41.

Rosoff, S. M., Pontell, H. N., \& Tillman, R. (2002). Profit without honor: White collar crime and the looting of America (pp. 37-41). Upper Saddle River, NJ: Prentice Hall.

Savelsberg, J.J. (1999). Human nature and social control in complex society: A critique of Charles Tittle's control balance. Theoretical Criminology, 3, 331-338.

Segalla, M., Rouzies, D., Besson, M., \& Weitz, B. A. (2006). A cross-national investigation of incentive sales compensation. International Journal of Research in Marketing, 24, 419-433.

Shichor, D., Gaines, L., \& Schoepfer, A. (2012). Reflecting on White Collar and Corporate Crime: Discerning Readings. Long Grove, IL: Waveland Press, Inc.

Simon, D. R., \& Eitzen, D. S. (2002). Elite deviance. Boston, MA: Allyn and Bacon.

Simpson, S. S. (2013). White collar crime: A review of recent developments and promising directions for future research. Annual Review of Sociology, 39, 309-331.

Sutherland, E. H. (1941). Crime and business. The Annals of the American Academy of Political and Social Science, 217, 112-118.

Sutherland, E. H. (1947). Principles of Criminology. Philadelphia, PA: J. B. Lincott.

Sutherland, E. H. (1949). White Collar Crime. New York: Dryden Press.

Tittle, C. R. (1995). Control balance: Toward a general theory of deviance. Boulder, CO: Westview Press, Inc.

Tittle, C. R. (2004). Refining control balance theory. Theoretical Criminology, 8, 395-428.

Topalli, V., \& Wright, R. (2013). Affect and the dynamic foreground of predatory street crime. Affect and cognition in criminal decision making, $42-57$.

Walters, G. D. (2003). Changes in criminal thinking and identity in novice and experienced inmates: Prisonization revisited. Criminal Justice \& Behavior, 30, 399-421.

Weinberg, S. L., \& Abramowitz, S. K. (2008). Statistics using SPSS: an integrative approach. Cambridge University Press.

Wood, P. B., \& Dunaway, R.G. (1997). An application of control balance theory to incarcerated sex offenders. Journal of the Oklahoma Criminal Justice Research Consortium, 4.

Wright, R. F. (2000). Strategies for avoiding the micro management trap. Management Decision, 38, 362-364. 